\title{
Review
}

\section{Traditional Arabic and Islamic Medicine, a Re-emerging Health Aid}

\author{
Hassan Azaizeh', Bashar Saad ${ }^{1,2,3}$, Edwin Cooper $^{4}$ and Omar Said ${ }^{1,5}$
}

${ }^{1}$ The Galilee Society R\&D Center, P.O. Box 437, Shefa-Amr 20200, ${ }^{2}$ Qasemi Research Center, Al-Qasemi

Academic College, Baga Algharbiya, Israel, ${ }^{3}$ Faculty of Allied Medical Sciences, Arab American University Jenin, P.O. Box 240, Jenin, Palestine, ${ }^{4}$ Laboratory of Comparative Neuroimmunology, Department of Neurobiology, David Geffen School of Medicine at UCLA, Los Angeles, CA, USA and ${ }^{5}$ Antaki Center for Herbal Medicine Ltd, Kufur Kanna (Cana of Galilee), Israel

Complementary medicine is a formal method of health care in most countries of the ancient world. It is expected to become more widely integrated into the modern medical system, including the medical curriculum. Despite the perception of modern medicine as more efficacious, traditional medicine continues to be practiced. More than $70 \%$ of the developing world's population still depends primarily on the complementary and alternative systems of medicine (CAM). In rural areas, cultural beliefs and practices often lead to self-care, home remedies or consultation with traditional healers. Herbal medicine can be broadly classified into four basic systems as follows: Traditional Chinese Herbalism, Ayurvedic Herbalism, Western Herbalismwhich originally came from Greece and Rome to Europe and then spread to North and South America and Traditional Arabic and Islamic Medicine (TAIM). There is no doubt that today the concept of Arabic traditional herbal medicine is a part of modern life in the Middle East, and it is acquiring worldwide respect, with growing interest among traditional herbalists and the scientific community. TAIM therapies have shown remarkable success in healing acute as well as chronic diseases and have been utilized by people in most countries of the Mediterranean who have faith in spiritual healers. TAIM is the first choice for many in dealing with ailments such as infertility, epilepsy, psychosomatic troubles and depression. In parallel, issues of efficacy and safety of complementary medicine have become increasingly important and supervision of the techniques and procedures used is required for commercial as well as traditional uses. More research is therefore needed to understand this type of medicine and ensure its safe usage. The present review will discuss the status of traditional Arab medicine (particularly herbal medicine), including the efficacy and toxicity of specific medicinal preparations, with an emphasis on the modern in vitro and in vivo techniques.

Keywords: Arab herbal medicine - efficacy - toxicity

\section{Traditional Arabic and Islamic Medicine Joins TCM, CAM, Kampo and Ayurveda}

There are several well-known and established medicinal plant heritages worldwide including the Kampo, TCM, TIM and Ayurveda. There has been increased global

For reprints and all correspondence: Dr Hassan Azaizeh or Prof. Bashar Saad, The Galilee Society R\&D Center, P.O. Box 437, Shefa Amr 20200, Israel. Tel: +972-4-9504523/4; Fax: +972-4-9504525; E-mail: bsaad@gal-soc.org or hazaizi@gal-soc.org interest in traditional medicine and there are efforts underway to monitor and regulate herbal drugs and traditional medicine. China has been successful in promoting its therapies with more research and a science-based approach, while Ayurveda still needs more extensive scientific research and evidence bases. Kampo medicine is widely practiced in Japan, where it is fully integrated into the modern health care system. Kampo is based on traditional Chinese medicine but adapted to Japanese culture. With only slight modifications, it has been 
adopted also in Taiwan and exported from Taiwan to the West. Kampo spread rapidly during the period 1985-95; after that, the number of practitioners stabilized at a nearconstant level $(1,2)$. By 1985, it was reported that about $20-25 \%$ of the medical doctors in Japan were prescribing some herbal medicines in their practice. However, as pointed out by Terasawa Katsutoshi, only about 100 or so doctors were routinely prescribing Kampo medicines to their patients. The proportion of doctors that provide some Kampo medicines has risen to about $50 \%$ or more by some estimates, with a proportional increase in Kampo specialists by more than 200. In addition, there are about 10000 pharmacies in Japan that dispense herbal formulas. In Japan, unlike Western countries, some part of Kampo remedies and acupuncture are covered by public health insurance $(1,2)$. Therefore, Japanese practitioners of Kampo and acupuncture would object to their inclusion in Complementary and Alternative Medicine (CAM) and would rather regard themselves as belonging to the authentic traditional medicine. Ayurveda, traditional Indian medicine (TIM) and traditional Chinese medicine (TCM) remain the most ancient yet living traditions.

The history and development of TCM in Taiwan started during the end of the Ming dynasty when largescale migration from Mainland China took place (3). The migrants brought with them a 2000 year old knowledge of TCM, complemented by the rich flora and fauna of Taiwan and the local knowledge of the aboriginal people. TCM has now become the highest priority in the Taiwan's blueprint for the development of biotechnology. With thousands of years of accumulated knowledge and experience in herbal medicine, there is a will to preserve it at any cost, although in early communist China it was discouraged. A utilization pattern for herbal medicine is just emerging in Taiwan. Uninformed patients, unscrupulous traders, adulterated preparations, unlicensed practitioners and illegal sources for herbal medicines have been blamed for creating a bad image of herbal medicine use in Taiwan $(4,5)$. The decision to cover Chinese Herbal Medicine (CHM) treatment under Taiwan's National Health Insurance (NHI) in 1992 had a big impact on the pattern of CHM unitization in Taiwan. Some researchers tried to find some link between the TCM and Ayurveda from the Indian subcontinent and their integration with other systems of medicine, including Western medicine, to realize the concept of sustainable medicine (6). In this aspect, several herbal medicines for potential steroidogenic activity have been screened both in vivo and in vitro to analyze their effect on steroid hormones.

Traditional Chinese herbal therapy can be characterized by the use of a large number of multi-herb formulae. To provide modern and Western scientists who do not possess background knowledge of Chinese literature and culture easy access to information, a database with more than 11000 traditional Chinese herbal formulae was constructed (6). All information was then translated into understandable scientific terms in English. Traditional Arabic and Islamic Medicine Joins (TAIM), on the other hand, is based on single plant species or a mixture of a small number of local plant species.

According to Olalde Rangel et al. (7), recent past and current naturalists and phytotherapeutic practitioners share a long and impressive tradition of knowledge and pride in curing illnesses. These qualities have been substantiated by the success of Chinese, Kampo, Ayurvedic, Chumash or Mayan among many other traditional medicines. From these traditional medicines it has been demonstrated that every culture is capable of understanding and 'inventing' the meaning of disease and finding probable cures (7). They may even be different from our modern medical views. The variety and extent of cultures to provide answers to traditional medicines and to unsolved pathologies are firmly grounded in the curiosity and observational capabilities of humans. To ensure this culture, there are collective factors, 'a background of extensive family practice in traditional medicine' crucial in the transmission and survival of medicinal plant knowledge among ethnic groups. However, there is a possible curtailment of the wisdom and therapies of traditional medicines that comes with geographical and ethnic boundaries. In addition, the number of plants, potential formulations or properties is a formidable concern for individual caregivers or groups to understand, store and transmit (7).

TAIM started hundreds of years ago and were used until recently in many of the primary books in libraries throughout Europe. Research into the TAIM herbs has been conducted in many Arab countries such as Syria, Morocco, Yemen, Egypt and others. The most recent surveys conducted on the potential uses of plant species in the Mediterranean region by ethnopharmacologists recorded 250-290 plant species belonging to different families still in use $(8,9)$. The remedies are administered by practitioners in forms of standard decoction prepared by boiling plant parts in hot water, infusion in water or oil or inhalation of essential oils. It is also taken as juice, syrup, roasted material, fresh salad or fruit, macerated plant parts, oil, milky sap, poultice and paste. In recent years, remedies based on TAIM herbs have been tested in cooperation with physicians and started to be routinely prescribed in Europe and in Mediterranean countries to their patients.

According to the World Health Organization (WHO), more than three-quarters of the world's population rely upon traditional medicine, mainly herbs (medicinal plants), for health care. Phytotherapy existed in one way or another in different cultures/civilizations, but the systematic and comprehensive works of Ibn Sina (Avicena in the West) in the form of Al-Qanun-fil-Tib (Canon of Medicine) occupies an eminent place in the 
history of medicine. This book has remained relevant over 600 years. During the 15th and 16th centuries alone it was published more than 35 times. In addition to the use of plants in their crude form for health care, they have been the main source for chemical drugs. Today there is a revival of interest in the use of medicinal plants in the form of standardized extracts/botanicals partly due to the high cost involved in the development of patentable chemical drugs and their multiple side effects. Botanicals such as Ispaghol, Garlic, Ginseng, Ginger, Ginkgo, St John's Wort, Mucuna prureins and Saw palmetto are gaining popularity for the purpose of health care. The impact of journals publishing data on medicinal plants is increasing and there is a rising trend to include phytotherapy in the curriculum of medical schools in North America and Europe. Over 70\% of German physicians prescribe herbs, and St. John's Wort is more commonly used than any chemical medicine to treat mild to moderate depression. Phytotherapy is considered relatively safe as it contains multiple chemicals with a specific composition acting as 'effect-enhancing and/or side-effects neutralizing', though there is limited scientific evidence for this assumption. Multidisciplinary team work including ethnobotanists, pharmacologists, physicians and phytochemists is essential for the fruitful outcome of medicinal plants research, and such international symposia as the aforementioned conference help to achieve this goal.

\section{Revival and Preservation of TAIM Knowledge}

Parallel to the increasing interest in 'modern' CAM therapies and the historical importance of TAIM, there is a similar trend in research activities dealing with the efficacy and safety of medicinal plants in the Middle East. Historical and current studies indicate that the Eastern region of the Mediterranean has been distinguished for long periods with a rich inventory of natural medicinal herbs. It is well documented that TAIM has contributed greatly to the development of modern medicine in Europe and remains one of the closest forms of original European medicine. In recent years researchers at the Galilee Society Research and Development Center, in cooperation with different institutes, have published more than 20 articles and review papers in peer reviewed Journals on this subject (8-16). These articles demonstrate the importance of traditional Arabic medicine and indicate that the Eastern region of the Mediterranean has been distinguished from other regions by a rich inventory of complementary alternative medicine, in particular herbal medicine. The data collected during these studies indicated that 200-250 herbs are still used in treating human diseases and are sold or traded in market places in the Mediterranean region or internationally. Some of these plant species have been investigated and bioactive ingredients extracted to treat various human diseases and as botanical pesticides (17-20).

The modern use of Arab botanical medicines has historical roots in ancient Arabic medicine. Arab herbalists, pharmacologists, chemists and physicians in the middle ages adopted the ancient medicinal practices of Mesopotamia, Greece, Rome, Persia and India. Medical innovations introduced by Arab physicians included: the discovery of the immune system, the introduction of microbiological science and the separation of medicine from pharmacological science. Recent ethnopharmacological surveys conducted by different groups in the Middle East support the necessity of proper handling of herbal medicine used in TAIM which requires suitable regulation and licensing in order to ensure supply of appropriate and safe products $(8,9)$. Fortunately, today there is a countertrend underway to preserve natural botanical resources through an increasing emphasis on conservation by way of botanical gardens, greenhouses, herbariums, tissue cultures, propagation and seed banks.

In an effort to help revive and preserve the knowledge of TAIM, an international conference on the current state of research and practice in the field was organized in 2007. This three-day conference took place in Amman, Jordan during August 8-10, and included an exhibition and poster session. The conference intended to: (i) establish an institution to serve as a network for all stakeholders in TAIM, as a prerequisite to revitalizing this important subject and to coordinate research and different activities in this field; (ii) revive the heritage of TAIM in order to present it in its normal environment, in order to release it from the political restrictions of the Middle East, (iii) revitalize this heritage as a scientific discipline and raise awareness of TAIM; (iv) explore the economic and sustainability aspects of this heritage and encourage investment to develop pharmaceutical products based on this culture and (v) increase the number of practitioners and quality of the practice of TAIM by training new and existing practitioners (21). The conference was designed for research scientists, local and regional traditional healers, international pharmaceutical and medical research companies, medical doctors, ethnopharmacologists and other parties interested in the study of traditional Arabic and Islamic medicine. All bodies and institutions, research centers and interested parties working in the field of Arab medicinal plants were invited to participate in the conference, which was structured into six sessions. Discussions touched on the historical and cultural aspects of Arabic Islamic medicine and its contribution to modern medicine and to human wellbeing. The global scientific research on medicinal and aromatic plants, pharmaceutical research, clinical trials, as well as international legislation and intellectual property rights on Arabic and Islamic medicinal plants of the region were also reviewed. Each of the six sections 
discussed a different issue related to TAIM. Their main points are delineated as described subsequently.

\section{Ethnopharmacology of Medicinal Plants used in TAIM}

Historical and current studies indicate that the Eastern region of the Mediterranean has been distinguished from other regions by a rich inventory of CAM, in particular herbal medicine. Data also indicate that there is a flourishing and well-developed trade of herbs, some of which are rare or endangered species. Unfortunately, with regard to the status of the herbalists' knowledge, herbal medicine in our region is mostly prescribed symptomatically by ethnopharmacologists; that is, based on signs and symptoms alone, rather than on a full understanding of the underlying disease. In other cases, herbs used today may not even correspond to the plants described originally in the old literature, as the former are cultivated from herbs that went through different breeding procedures over several centuries (10).

\section{TAIM Heritage}

During the 8th until the 11th centuries, Arab physicians upgraded the existing knowledge about herbs and their potential medical efficacy and safety. Their greatest contributions to modern medicine were the immune system and introduction of microbiological science [(22), for more details, see review in Ref. (12)]. The Eastern region of the Mediterranean has been distinguished throughout generations by a rich inventory of natural medicinal herbs $(8,22-24)$. The Middle Eastern region was covered with $>2600$ plant species of which $>700$ were noted for their use as medicinal herbs or botanical pesticides. Unfortunately, recent ethnopharmacological surveys reveal that 200-250 plant species are still in use in Arab traditional medicine for the treatment of various diseases (8,25-28). There are several factors endangering plant diversity or even causing eradication of these herbs, including habitat loss, habitat degradation and overharvesting (29). Recent ethnopharmacological surveys conducted by different groups in the Middle East support the necessity of proper handling of herbal medicine which requires suitable regulation and licensing in order to ensure supply of suitable and safe products $(13,25)$. Medicinal plants in the Middle Eastern region and worldwide are becoming increasingly rare due to the ongoing destruction of their natural habitat and detrimental climatic and environmental changes. As a result, it is predicted that in semi-arid regions such as the Middle East, a number of species will disappear within the next 10 years, particularly in desert or dry areas. This gives an added sense of urgency to initiate preservation programs of regional medicinal plant genetic resources (15).

\section{Al-Maissam}

Al-Maissam, the Galilee Society's Medicinal Plants Center, was established based on in-depth study of TAIM and intended to provide an efficient model for preserving and developing traditional knowledge on Arabic medicinal plants. A comprehensive survey of traditional Palestinian herbal medicine practitioners was conducted in order to assess the current status of the herbal medicinal practice $(8,10)$. Results demonstrated that, unfortunately, most practitioners have very limited knowledge about herbal medicine and younger practitioners had even poorer knowledge than their older counterparts, while many practitioners are turning to 'mystical' or 'magical' methods of healing. In addition, plants used in certain regions are not used in others, the education level of practitioners is in decline, some medicinal plant species are endangered and plant mixtures are of poorer quality and less variety in comparison to the past $(8,10)$. As a result of this survey, it became clear that indigenous plant knowledge is disappearing across recent generations. The conclusion to be drawn was clear-that traditional Palestinian medicinal practice is suffering and that in time, if action is not taken to ensure its survival, important parts of this heritage may disappear completely and a wide variety of methods of treating various diseases may be lost to humanity. The first effort made by the Galilee Society to revive the Palestinian traditional medicinal heritage was the establishment of Al-Maissam. Al-Maissam, the Galilee Society's Medicinal Plants Center, was founded in 1999 with main objectives of preserving and rediscovering the ancient Arab legacy of herbal medicine. Its activities include preserving native medicinal plants, preserving and advancing ethnobotany of the native flora, and spreading this knowledge to all levels of society (especially among the younger generation). It is a unique biotechnology center and the first in our region where modern advanced research is used with traditional Arab herbal medicine, rendering it compatible with modern phytotherapy.

\section{In vitro Studies}

In general, in vitro test systems represent the first phase of the evaluation procedure. The in vitro cell culture methods have the advantage of relatively well-controlled variables and are generally accepted as a very effective method for safety testing. Advantages of these systems over classical methods (such as long term studies on experimental animals) include relatively well-controlled variables, decreased costs, a reduced time to completion, and reduced numbers of animals necessary to complete the study. The fact that cells and tissues in vivo do not exist in isolation but communicate with and are interdependent of neighboring tissue makes it essential to simulate the in vivo situation $(13,14)$. 
Some studies on this subject were presented during the conference, (21) including anti-colon-cancer effects of Thymoquinone, a natural drug with pro-oxidant activities. Also, promising data was shown about Salograviolide A isolated from the indigenous Lebanese plant Centaurea ainetensis. Salograviolide A causes growth inhibition and cell death in skin cancer cells.

\section{In vivo and Clinical Trials}

The use of in vivo experimentation and clinical trials are important methods, and despite the limitations of animal experimentation, they are still crucial in herbal drug development. Developing a therapeutic remedy from herbal origins is a complex process that has to pass through various important preclinical steps. These steps include standardization of the herbal extract, providing evidence of pharmacological activity, and providing evidence of safety.

Pharmacological screening has to be carried out ultimately on laboratory animals and this has many ethical considerations regarding the proper conduct of such screening and the expected value of its outcomes. The use of laboratory animals is unavoidable but should be rationalized through careful planning. Preliminary in vitro testing should give some idea of the possible mechanisms of action and potential therapeutic usefulness of an herbal extract, but obviously has its shortcomings. Such tests provide no information regarding biotransformation of the extract in the body, pharmacokinetic aspects of absorption and fate. To determine potential therapeutic usefulness in a certain disease state, however, appropriate animal models have been developed that mimic the human condition to some extent. Animal models have been developed for many conditions, including hypertension, myocardial infarction, atherosclerosis, ischemia, bronchial asthma, arthritis, diabetes, Parkinsonism, depression, epilepsy, gastric ulcers, reflux oesophagitis, inflammatory bowel disease, cancer, etc. Extrapolation of results from animal to human should be carried out with great caution. Animal models only mimic the symptoms in humans, but not the etiology or the overall clinical picture. Thus, it is not possible to say that an extract, which lowers blood pressure in rats rendered hypertensive by L-NAME, where the hypertension is due to endothelial dysfunction, would function as well in a patient whose hypertension is due to any other cause. Streptozotocin induced diabetes in rat is not exactly the same as diabetes in humans: not only is the condition different in etiology, but the human response may be quite different from that of the rat, particularly since diabetes in humans is normally associated with a number of events that may not be seen in the rat.

The metabolism and pharmacokinetic behavior of active constituents may differ from species to species, and accordingly the interpretation of animal findings may not necessarily be applicable to humans. In general, therefore, animal models are artificially induced conditions said to be analogous to the human diseases they are intended to simulate, but they differ substantially from their human 'counterparts' in both cause and clinical course. This also holds true for toxicological studies. Such studies should always be performed according to international guidelines and are a prerequisite for evaluating the safety of potentially useful therapeutic agents.

\section{Market Authorization Regulations for Herbal Products}

Regulations are needed to ensure safety, quality and efficacy of herbal medicines. Countries define herbal medicines differently and have adopted various approaches to licensing, dispensing, manufacturing and trading these products. The main differences in the regulations governing herbal medicines in different countries were discussed at the conference. Within Europe, and according to the country using them, herbal medicines are either fully licensed as medicines with efficacy proven by clinical trials, or have a more simplified approach toward proof of efficacy. In the USA, most herbal products are considered dietary supplements and thus are not required to meet the more stringent standards for drugs specified in the Federal Food, Drugs and Cosmetic Act. These different approaches have resulted in differences in the availability of some herbal medicines.

\section{Acknowledgements}

The authors would like to thank Ms Arisha Ashraf and Ms Jamie Mandell from the Galilee Society, Shefa-Amr, Israel for their constructive comments.

\section{References}

1. Yu F, Takahashi T, Moriya J, Kawaura K, Yamakawa J, Kusaka K, et al. Traditional Chinese medicine and Kampo: a review from the distant past for the future. $J$ Int Med Res 2006;34:231-9.

2. WHO. 2001. Legal Status of Traditional Medicine and Complementary/Alternative Medicine: A Worldwide Review. http:// libdoc.who.int/hq/2001/WHO_EDM_TRM_2001.2.pdf.

3. Chen CF, Shum YC, Yang SP. The modernization of traditional Chinese medicine in Taiwan- past, present and future. In: Cooper EL, Yamaguchi N (eds). Complementary and Alternative Approaches to Biomedicine. Santiana Med, New York: Kluwer Academic/Plenum Publishers, 2004, 35-42.

4. Yeh CH, Tsai JL, Li W, Chen HM, Lee SC, Lin CF, et al. Use of alternative therapy among pediatric patients in Taiwan. Pediatr Hematol Oncol 2000;17:55-65.

5. Deng JF. Clinical toxicity of herbal medicine in Taiwan. In: Wang $\mathrm{HH}$, Li J (eds). Proceedings of the 7 th International Conference on Health Problems Related to the Chinese in North America. New York, 1994.

6. Kaphle K, Wu L-S, Yang N-YJ, Lin JH. Herbal medicine research in Taiwan. Evid Based Complement Altern Med 2006;3:149-55.

7. Olalde Rangel JA, Magarici M, Amendola F, del Castillo O. The systemic theory of living systems. Part IV: systemic medicine-the Praxis. Evid Based Complement Altern Med 2005;2:429-39. 
8. Said O, Khalil K, Fulder S, Azaizeh H. Ethnopharmacological survey of medicinal herbs in Israel, the Golan Heights and the West Bank region. J Ethnopharmacol 2002;83:251-65.

9. Azaizeh H, Saad B, Khalil K, Said O. The state of the art of traditional Arab herbal medicine in the Eastern region of the Mediterranean: a review. Evid Based Complement Altern Med 2006;3:229-35.

10. Azaizeh H, Fulder S, Khalil K, Said O. Ethnobotanical survey of local practitioners of the Middle Eastern region: the status of traditional Arabic medicine. Fitoterapia 2003;74:98-108.

11. Azaizeh H, Ljubuncic P, Portnaya I, Said O, Cogan U, Bomzon A. Fertilization-induced changes in growth parameters and antioxidant activity of medicinal plants used in traditional Arab medicine. Evid Based Complement Altern Med 2005;2:549-56.

12. Saad B, Azaizeh H, Said O. Tradition and perspectives of Arab herbal medicine: a review. Evid Based Complement Altern Med 2005;2:475-9.

13. Saad B, Azaizeh H, Abu Hijleh G, Said O. Safety of Traditional Arab herbal medicine. Evid Based Complement Altern Med 2006;3:433-9.

14. Saad B, Dakwar S, Said O, Abu-Hijleh G, Al Battah F, Kmeel A, et al. Evaluation of medicinal plant hepatotoxicity in co-cultures of hepatocytes and monocytes. Evid Based Complement Altern Med 2006;3:93-8.

15. Saad B, Azaizeh H, Said O. Arab botanical medicines. In: Ron Watson, Victor Preedy (eds). The Encyclopedia of Botanicals in Clinical Practice. 31-39.

16. Said O, Fulder S, Khalil K, Azaizeh H, Kassis E, Saad B. Maintaining a physiological blood glucose level with the help of 'Glucolevel', a combination of four anti-diabetes plants used in traditional Arab herbal medicine. Evid Based Complement Altern Med 2007;4:2.

17. Mansour F, Azaizeh H, Saad B, Tadmor Y, Abo-Moch F, Said O. The potential of Middle Eastern Flora as a source of new safe bioacaricides to control tetranychus cinnabarinus - the carmine spider mite. Phytoparasitica 2004;32:66-72.

18. Ljubuncic P, Azaizeh H, Portnaya I, Cogan U, Said O, Abu Saleh K, et al. Antioxidant activity and cytotoxicity of eight plants used in traditional Arab medicine. $J$ Ethnopharmacol 2005;99:43-7.

19. Azaizeh H, Kobaisy M, Dakwar S, Saad B, Shaqir I, Said O. Botanical pesticides as a source of safe bio-acaricides for the control of tetranychus cinnabarinus mites. Fitoterapia. Acta Phytopathologica et Entomologica Hungarica 2007;42:143-52.

20. Said O, Khalil K, Fulder S, Azaizeh H, Kassis E, Saad B. Safety, tolerability, and anti-obesity effects of weighlevel, a combination of Alchemilla vulgaris, Olea europaea, Mentha arvensis, and Cuminum cyminum L. J Integr Med Insights 2008 (in review).

21. Azaizeh H, Saad B, Cooper E, Said O. Traditional Arabic and Islamic medicine (TAIM) now join TCM CAM, Kampo and Ayurveda. Evid based Complement Altern Med 2007. doi:10.1093/ ecam $/$ nem 157.

22. Bin Murad I. Research into the History of the Medicine and Pharmacology of the Arabs. Beirut, Lebanon: Dar AlGarb AlIslami, 1991 (in Arabic).

23. AlTurkimany JOA. AlMoatamad Fi Aladweah Almofradah (The source of the single Pharmaceuticals). Revised by AlSaka M. Beirut, Lebanon: Dar AlKalam Publishing; 1993 (in Arabic)

24. Bacher W. Scham als Name Palastinas. Jewish $Q$ Rev 1906; 18:564-5.

25. Abu-Irmaileh BE, Afifi FU. Herbal medicine in Jordan with special emphasis on commonly used herbs. J Ethnopharmacol 2003;89:193-7.

26. Halberstein RA, Davis JE. Biosocial aspects of high blood pressure in the Bahamas. Hum Biol 1984;56:317-28.

27. Lev E, Amar Z. Ethnopharmacological survey of traditional drugs sold in Israel at the end of the 20th century. $J$ Ethnopharmacol 2000;72:191-205.

28. Lev E, Amar Z. Ethnopharmacological survey of traditional drugs sold in the kingdom of Jordan. $J$ Ethnopharmacol 2002;82:131-45.

29. Hamilton AC. Threats to plants: an analysis of centers of plant diversity. In: Touchell DH, Dixon KW (eds). Conservation into the 21 st Century. Proceedings of 4th International Botanic Gardens Conservation Congress. Vol. Perth, Australia: Kings Park and Botanic Garden, 1997, 309-22.

Received November 29, 2007; accepted May 9, 2008 


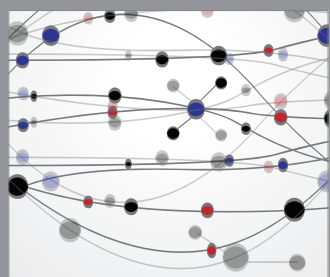

The Scientific World Journal
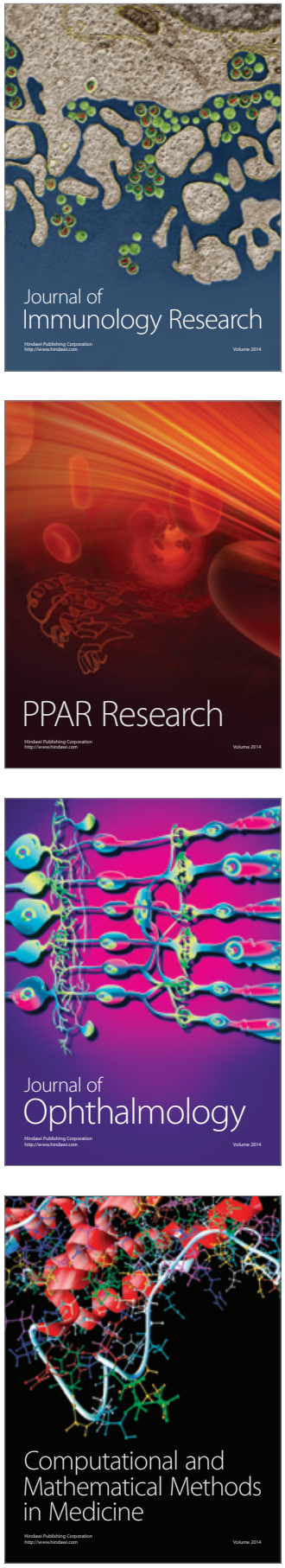

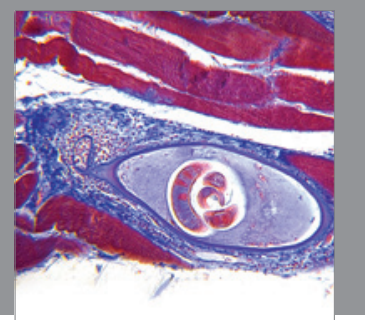

Gastroenterology

Research and Practice
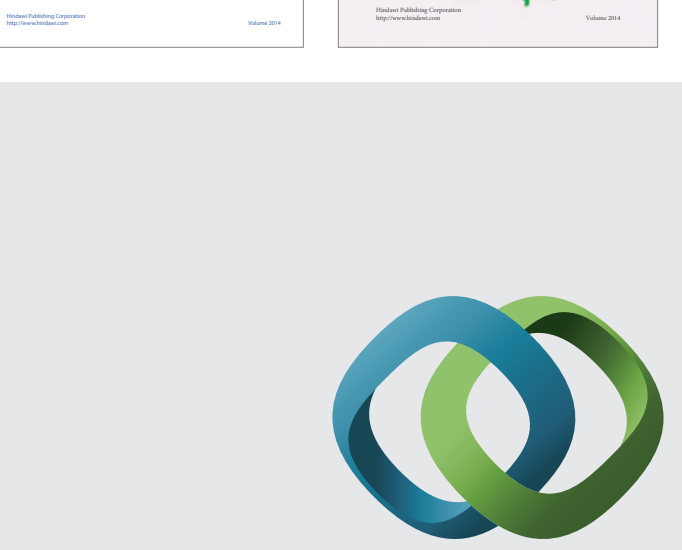

\section{Hindawi}

Submit your manuscripts at

http://www.hindawi.com
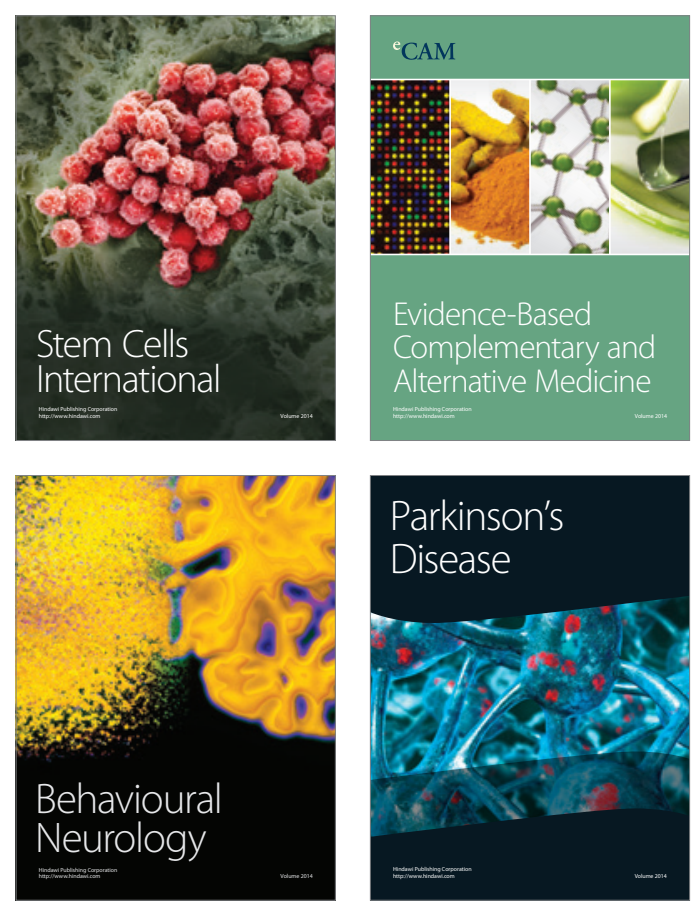

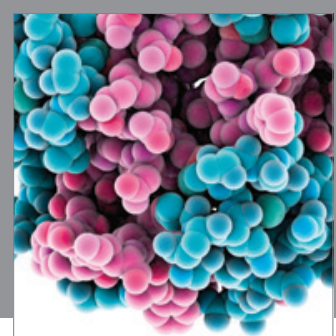

Journal of
Diabetes Research

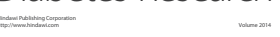

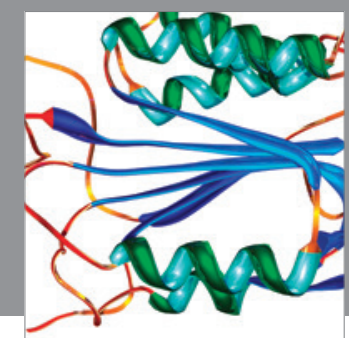

Disease Markers
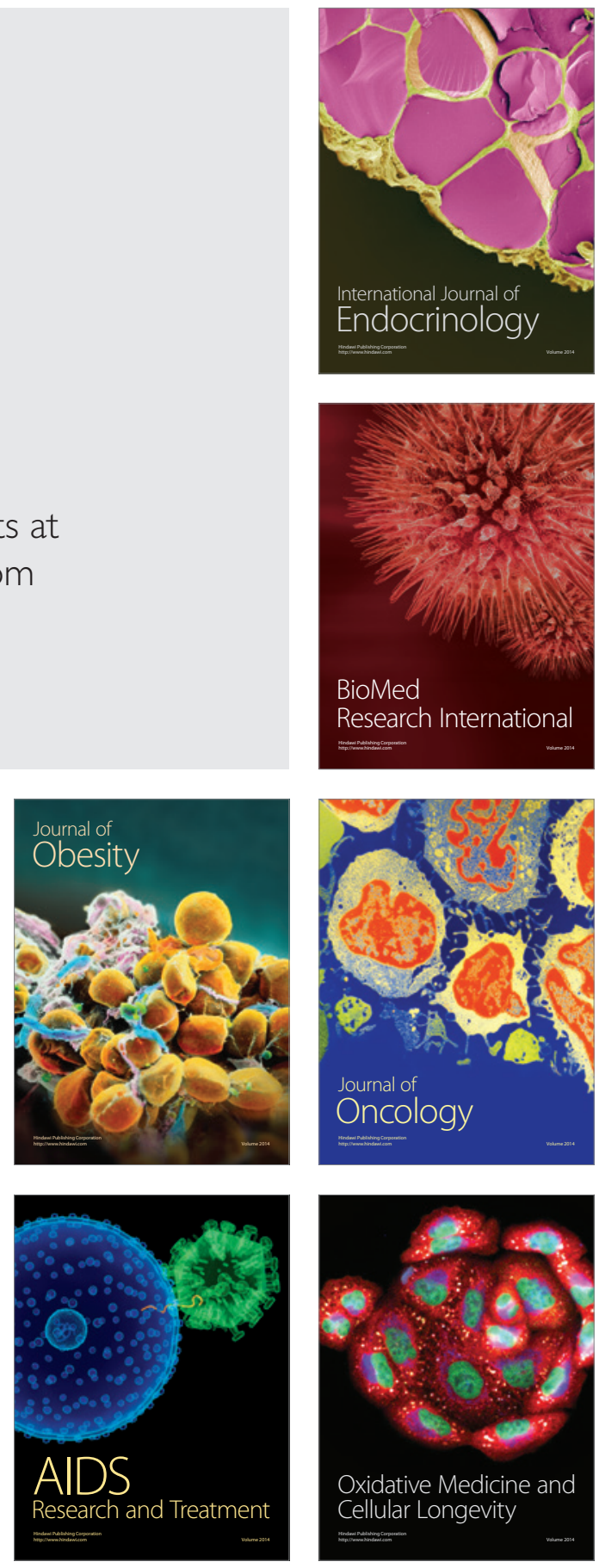